\title{
Mapping sediment thickness of the Abbottabad basin, Pakistan
}

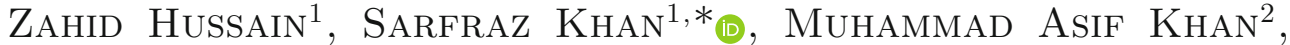 \\ Muhammad Waseem ${ }^{1}$ and Waqas Ahmed ${ }^{1}$ \\ ${ }^{1}$ National Centre of Excellence in Geology, University of Peshawar, Peshawar, \\ Khyber Pakhtunkhwa 25130, Pakistan. \\ ${ }^{2}$ University of Peshawar, Peshawar, Khyber Pakhtunkhwa, Pakistan. \\ *Corresponding author.e-mail: sarfraz_qau@yahoo.com
}

MS received 8 June 2017; revised 14 March 2018; accepted 27 March 2018; published online 20 November 2018

The Abbottabad basin is mainly composed of different loose and indurated sediments such as fine to medium grain silt and clay and large to medium sized boulders and cobbles, occupying a low land between the hills. These sediments are primarily stream deposits and variably compacted in the form of rock, suggested name Havelian group after their maximum thickness into Havelian area. Numerous streams converge at the Abbottabad intermontane basin from the north-northeast and join to form a single channel that passes through a narrow gorge on the western side of the Sirban hill. Geomorphically, the Abbottabad city is underlain by a thick sequence of loose Quaternary-Recent alluvial sediments, making it vulnerable to seismic hazards. This research determines the sediment thickness for the Abbottabad basin using a geophysical approach. In this regard, thirteen lithologic profiles were developed in the Abbottabad basin at different locations. These profiles were ultimately combined to develop a Fence diagram showing a generalized stratigraphic pattern of the Quaternary-Recent unconsolidated sediments in the basin. Standard Penetration Test (SPT) and H/V analysis were used to characterize the site and shear wave velocity at a different location of Abbottabad basin and surrounding area. Based on $\mathrm{H} / \mathrm{V}$ data (using Tromino Engy Plus instrument) Abbottabad basin and immediate surroundings have an average fundamental frequency from 0.5 to $9 \mathrm{~Hz}$, which represents the deposition of alluvial sediments (i.e., stiff and dense soil).

Keywords. Fence diagram; fundamental frequency; sediment thickness.

\section{Introduction}

Pakistan is located at the junction of the Eurasian and the Indian plates and is considered amongst one of the most seismically active zones in the world. The devastating earthquakes in the subcontinent have been a result of the ongoing collision between these two plates. The Indian plate is converging towards the Eurasian plate at a rate of $50 \mathrm{~mm}$ /year (Alvarez 2010). Major boundary faults such as the Main Karakoram Thrust (MKT), Main Mantle Thrust (MMT), Main Central Thrust (MCT), Main Boundary Thrust (MBT) and the Main Frontal Thrust (MFT) in northern Pakistan owe their origin to the collision-related deformation at the northern continental margin of the Indian plate (Tahirkheli et al. 1979). Pakistan has a seismicity history marked by several major 
earthquakes in the recent past, including the 1935 Quetta earthquake of magnitude 7.4, 1945 Makran earthquake of magnitude 8.0, 1974 Pattan earthquake of magnitude 6.0 and 2005 Muzaffarabad earthquake of magnitude 7.6 (MonaLisa et al. 2007).

This study is centered at the city of Abbottabad, which is amongst the northernmost major cities in Pakistan situated closest to the Himalayan plate boundary in the Lesser Himalayas. The proposed study area is located between the latitudes $34^{\circ} 9^{\prime}-34^{\circ} 14^{\prime} \mathrm{N}$ and the longitudes $73^{\circ} 12^{\prime}-73^{\circ} 17^{\prime} \mathrm{E}$, and has an average elevation $1125 \mathrm{~m}$, according to the survey of Pakistan toposheets 43F/04 and $43 / 08$. The location map of the study area is shown in figure 1. This study area lies in the footwall of Panjal Thrust, which is equated with MCT
(DiPietro and Pogue 2004). Important faults such as the Mansehra Thrust, MMT, BalakotMuzaffarabad-Bagh Thrust, Indus Kohistan Seismic Zone and the Jhelum Fault are situated at a distance of less than $100 \mathrm{~km}$ to the north and northeast of the Abbottabad city. MBT and Nathiagali Thrust are located to the south of the Abbottabad city within a close distance (Seeber and Armbruster 1979; Tahirkheli et al. 1979; Hussain et al. 2009). This tectonic setting of the Abbottabad city and the surrounding areas clearly show a high level of potential seismic hazards.

The geomorphic settings of Abbottabad city provide further evidence of the seismic vulnerability. Abbottabad is an intermontane basin, occupying a low land between ridges. Various streams originating from the surrounding mountains

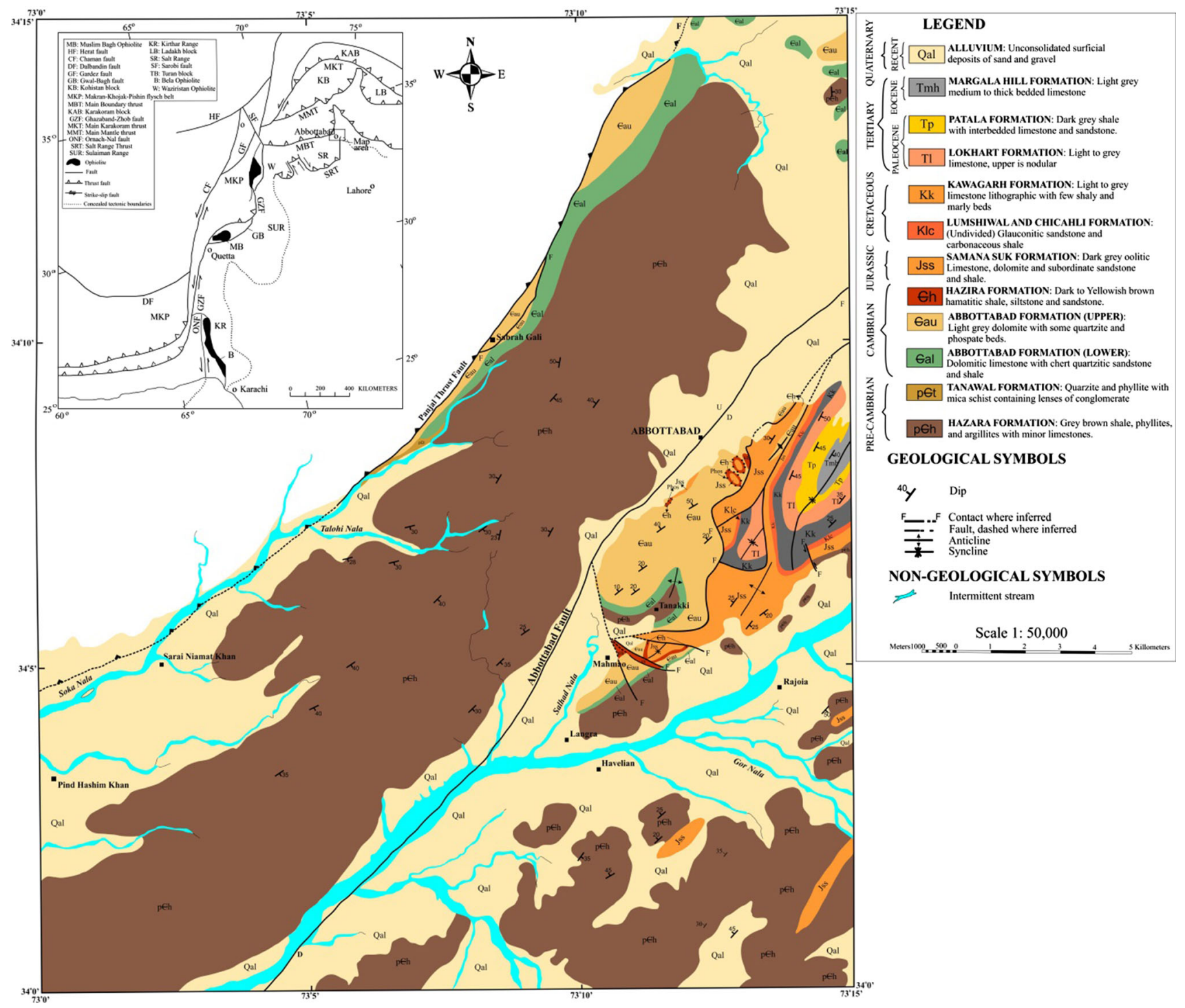

Figure 1. Geological map of the study area (modified after GSP 2002). 


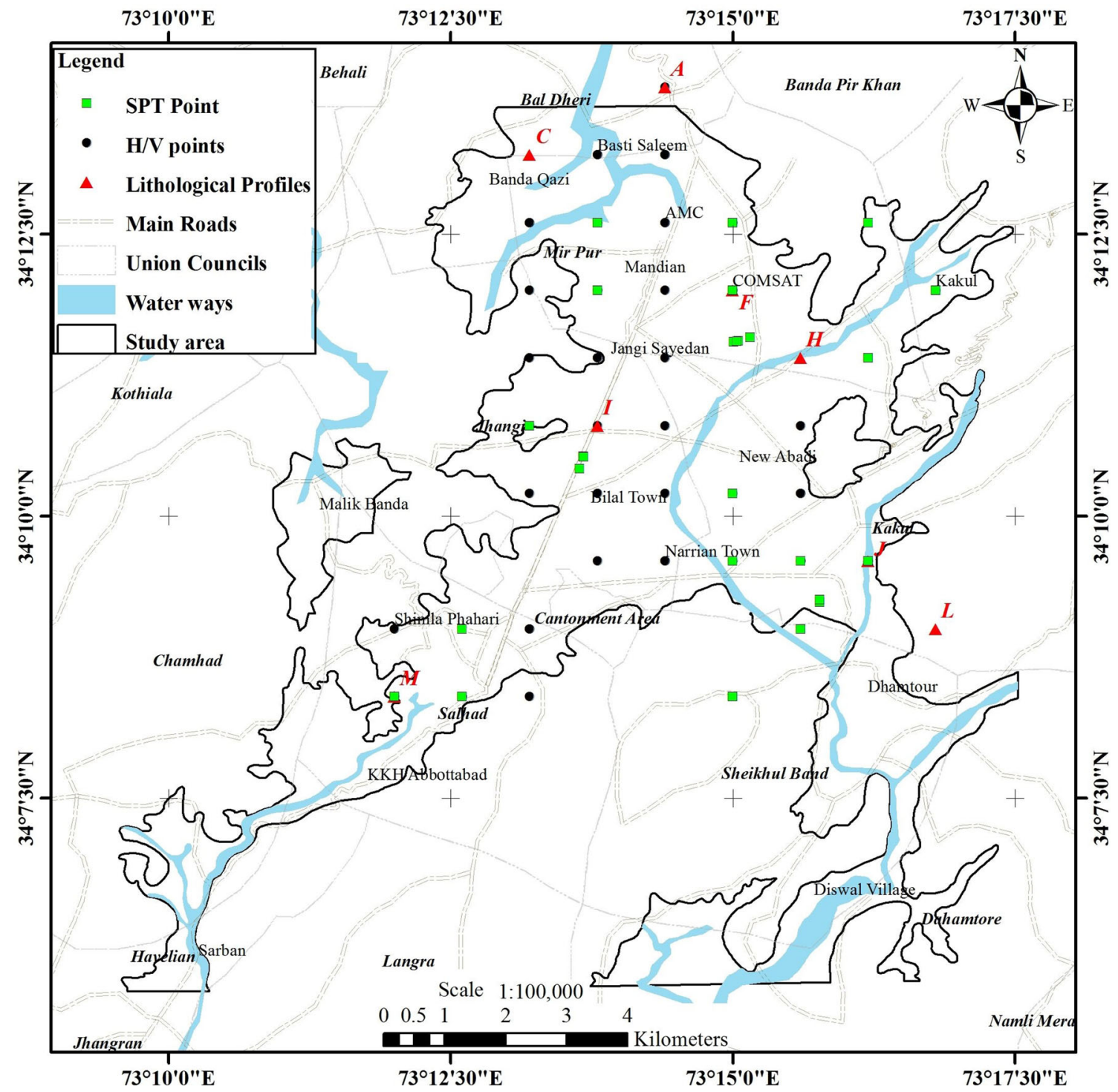

Figure 2. Location map of lithological profiles, $\mathrm{H} / \mathrm{V}$ data point and SPT data points.

converge in a relatively broad basin of Abbottabad. However, the southern exit from the basin is by a narrow gorge, on the western side of the Sirban hill. As a result, the Abbottabad basin is characterized by thick Quaternary alluvial sediments due to the streams feeding the basin (Latif 1970). The amplification of seismic waves critically depends upon the material through which they travel. The Abbottabad city built on Quaternary loose deposits is therefore vulnerable to the seismic amplification. The devastating Kashmir earthquake of October 2005 caused much damage to the buildings that occupied the central axis of the basin compared to the building located at the surrounding ridges (Shahzada 2011).

Abbottabad, being one of the cities that suffered damages in the October 2005 Kashmir earthquake warrants special attention for many reasons.
Firstly, the city hosts a population of around 2 million; secondly, it hosts a large number of educational institutions including engineering and medical colleges and a military academy. It's tectonic setting in Lesser Himalayas and above all, its location in an intermontane basin with thick deposits of Quaternary and younger sediments make the city vulnerable to pronounced seismic shaking.

This paper focuses on determining the geomorphological settings and sediment thickness for the Abbottabad basin. In this regard, we present Fence diagram and microtremor data of Tromino Engy Plus and use $\mathrm{H} / \mathrm{V}$ spectral ratio method to determine the distribution and thickness of sediments in the Abbottabad basin. Simultaneously, derivation of the empirical relationship between the main resonance frequencies and 


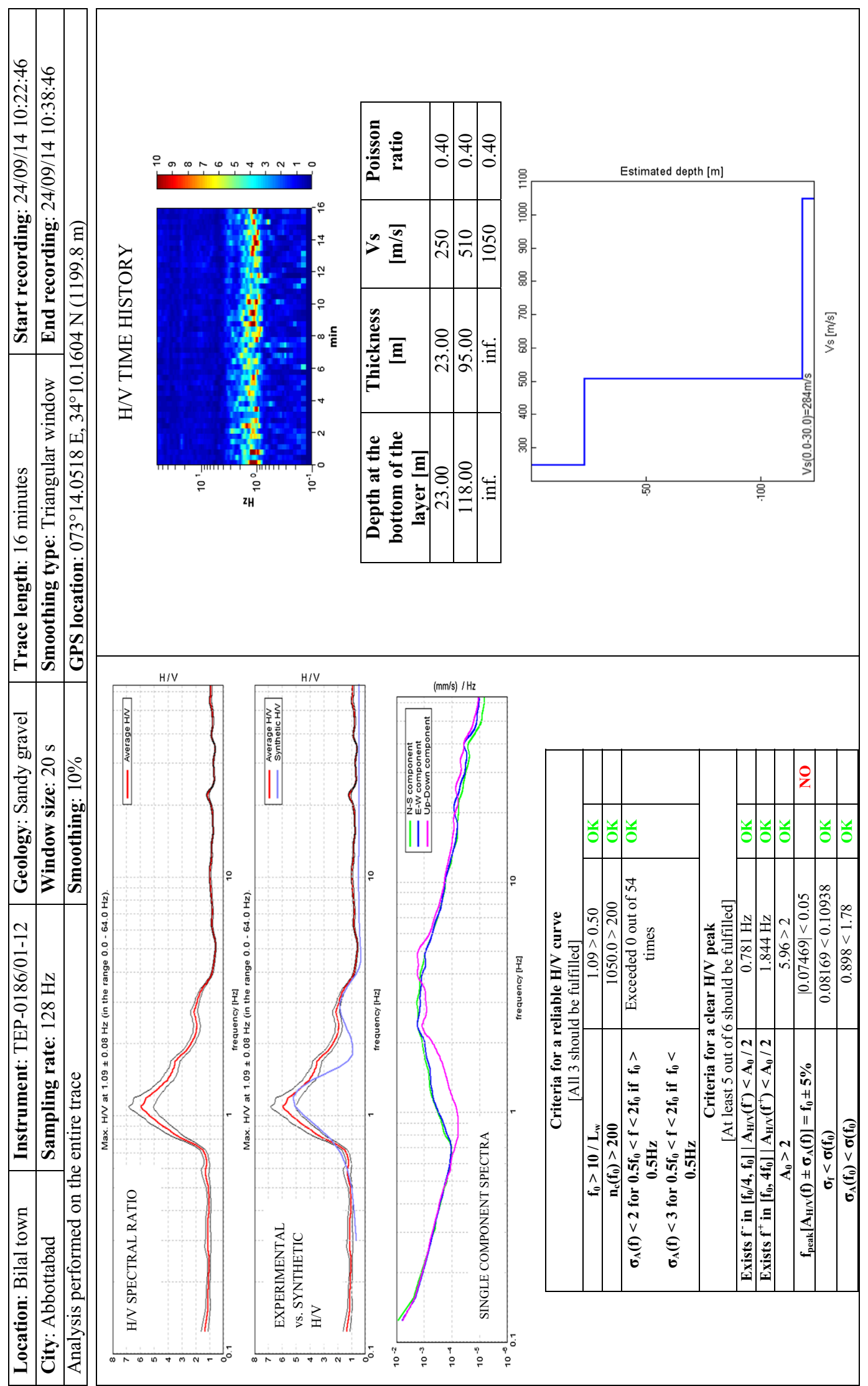




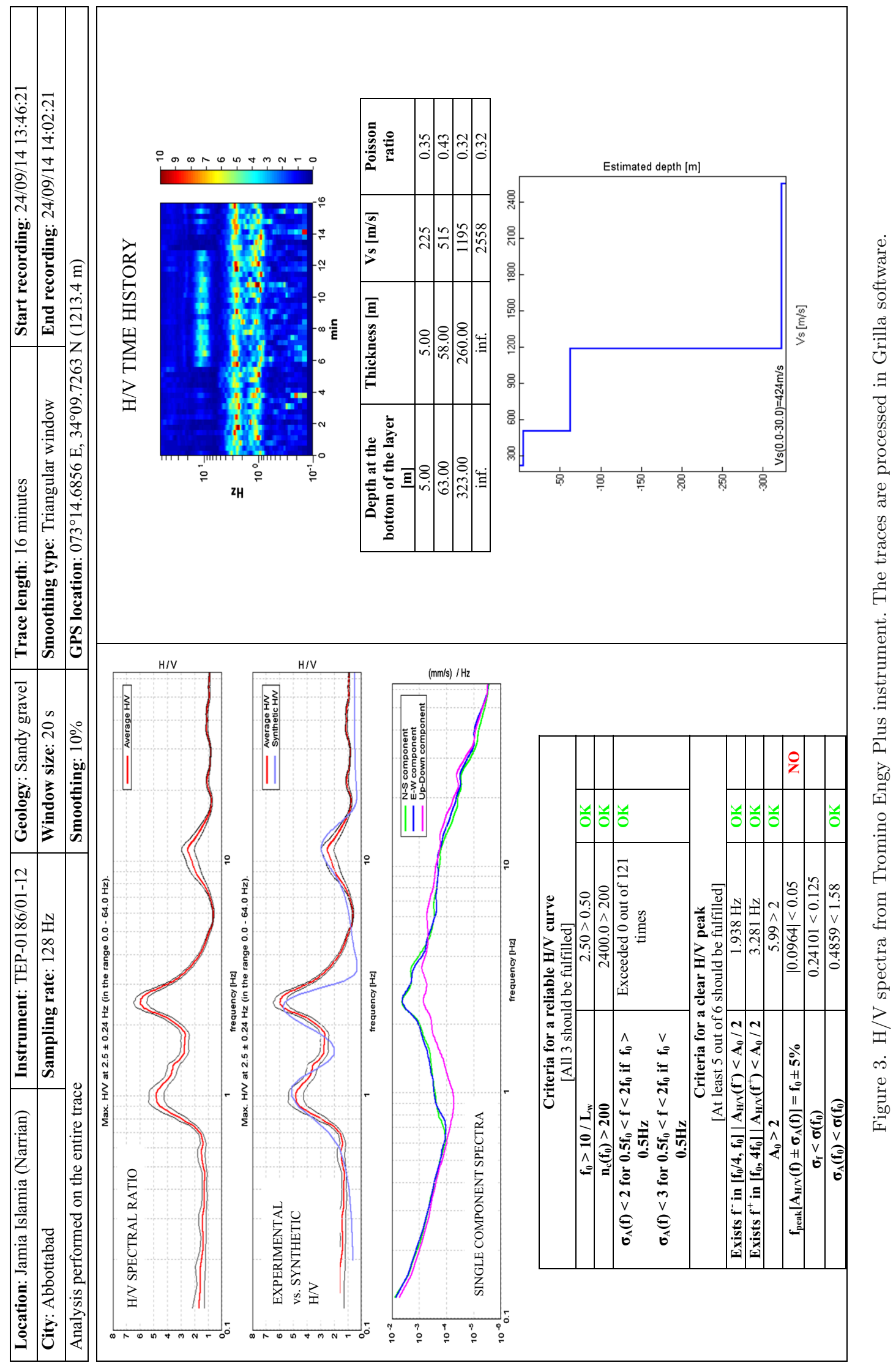




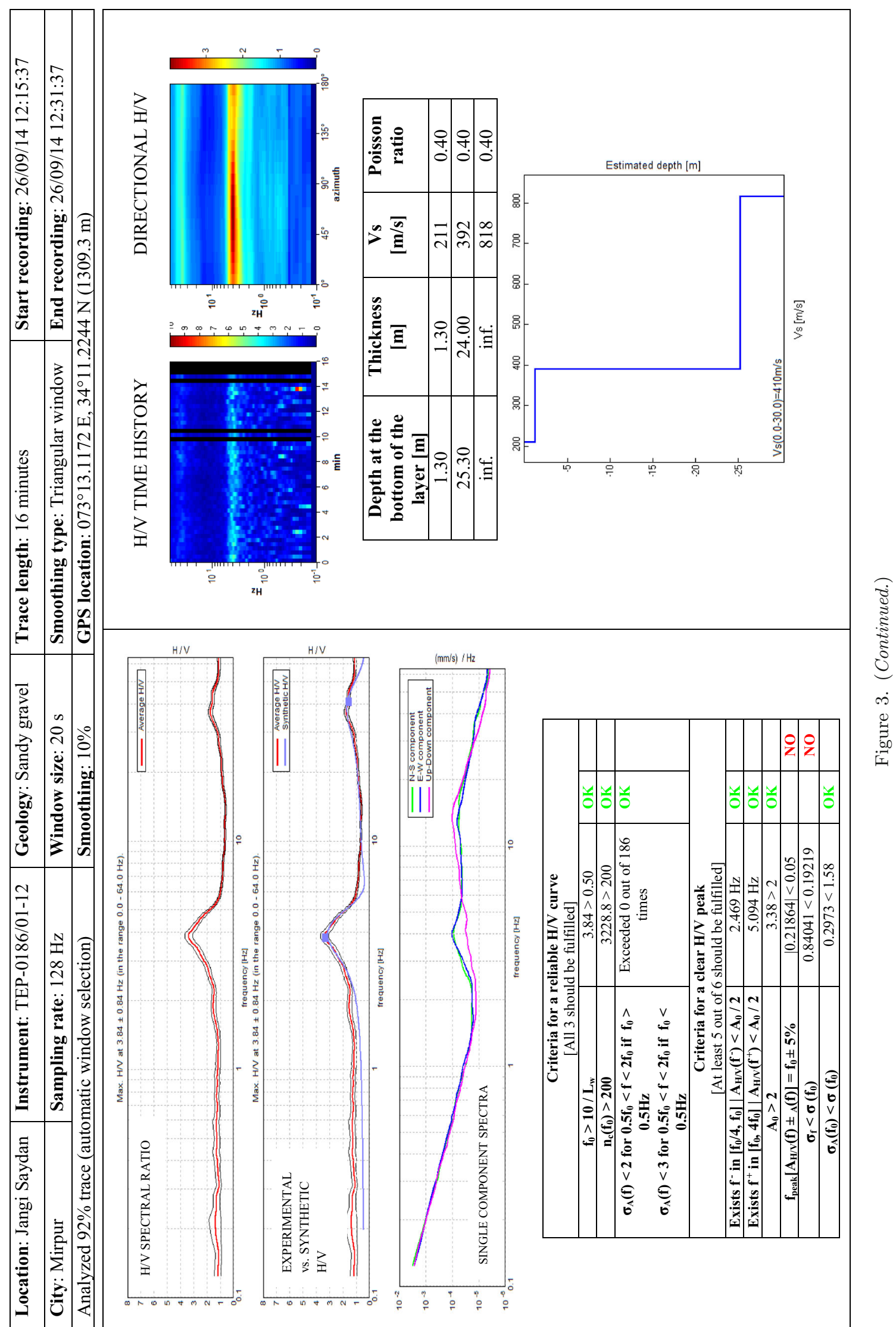


overburden thickness obtain by $\mathrm{H} / \mathrm{V}$ spectral ratios in the Abbottabad basin remained also as one of the prime objectives.

\section{Data collection}

Ambient noise measurement survey was run at 81 sites (figure 2) in Abbottabad basin using Tromino Engy Plus, a mini portable seismograph recently developed and manufactured in Italy. For the data recording and processing, Grilla Software (2012) was used. The data was recorded at a sampling rate of $128 \mathrm{~Hz}$ for $30 \mathrm{~min}$ in Grilla trace format. Each digital signal file was processed in Grilla Software (2012) using SESAME (2004) criteria (figure ). Detailed information about the thickness of the subsurface sedimentary covers is also available from 21 well logs drilled by National Engineering Services of Pakistan (NESPAK).

Road and stream cuts in the study area (Abbottabad basin) are selected to deduce information regarding the nature of the sediments and their lateral distribution in the basin and to construct lithological profiles.

\section{Methodology}

\subsection{Local lithological profiles}

Altogether 10 lithological profiles (figures $4 \mathrm{a}-\mathrm{j}$ ) were developed in the Abbottabad basin at different locations (figure 2). These profiles were ultimately combined to develop a Fence diagram showing a generalized stratigraphic pattern of the Quaternary to Recent unconsolidated sediments

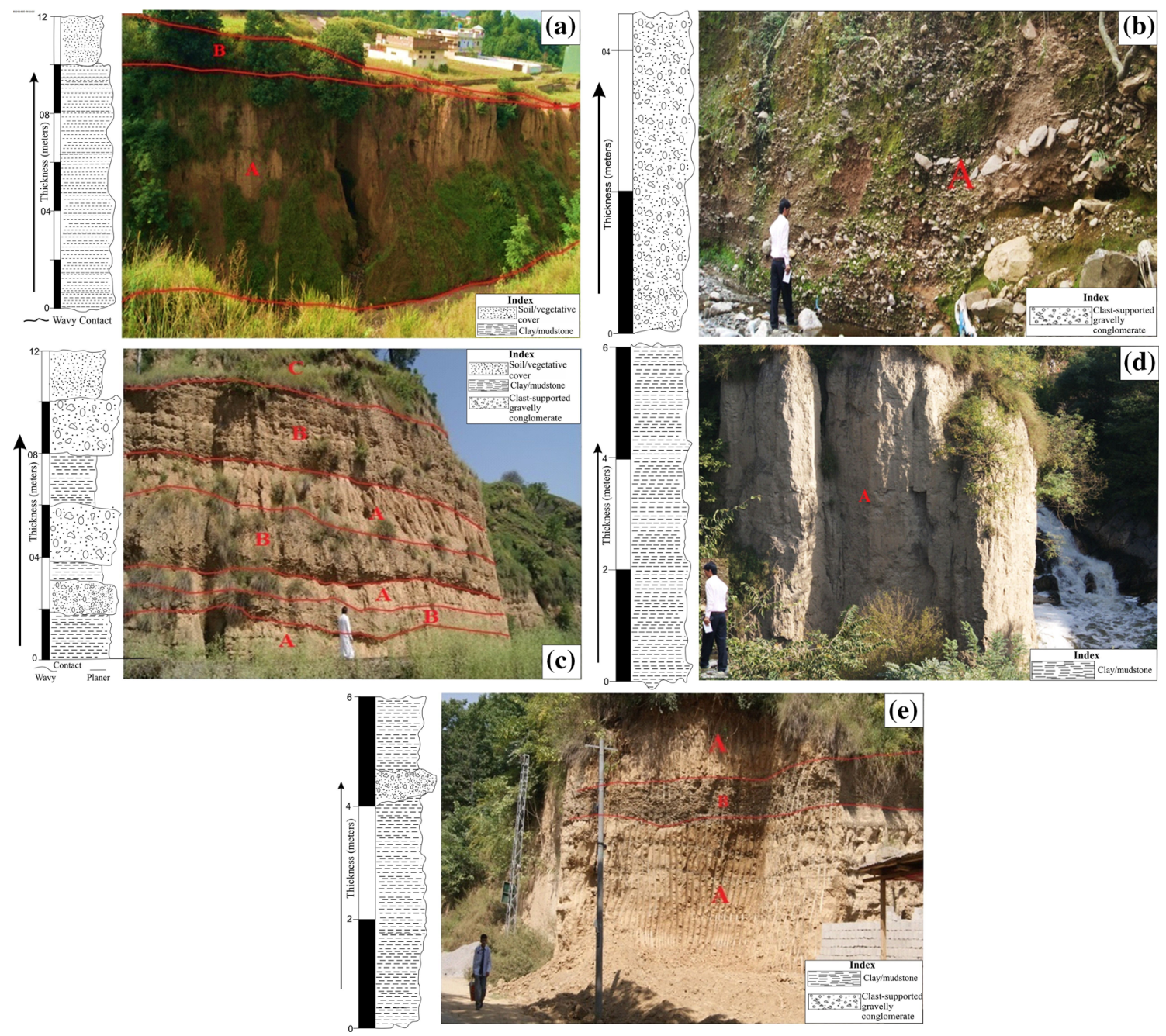

Figure 4. Lithological profiles at (a and b) Mirpur area; (c) Banda Ali Khan; (d) Marrie road; (e) Supply area; (f) Ayub Medical College; (g) Harnoi area; (h) Nawashahr; (i) Jhangi Saydan; and (j) Kakul. 

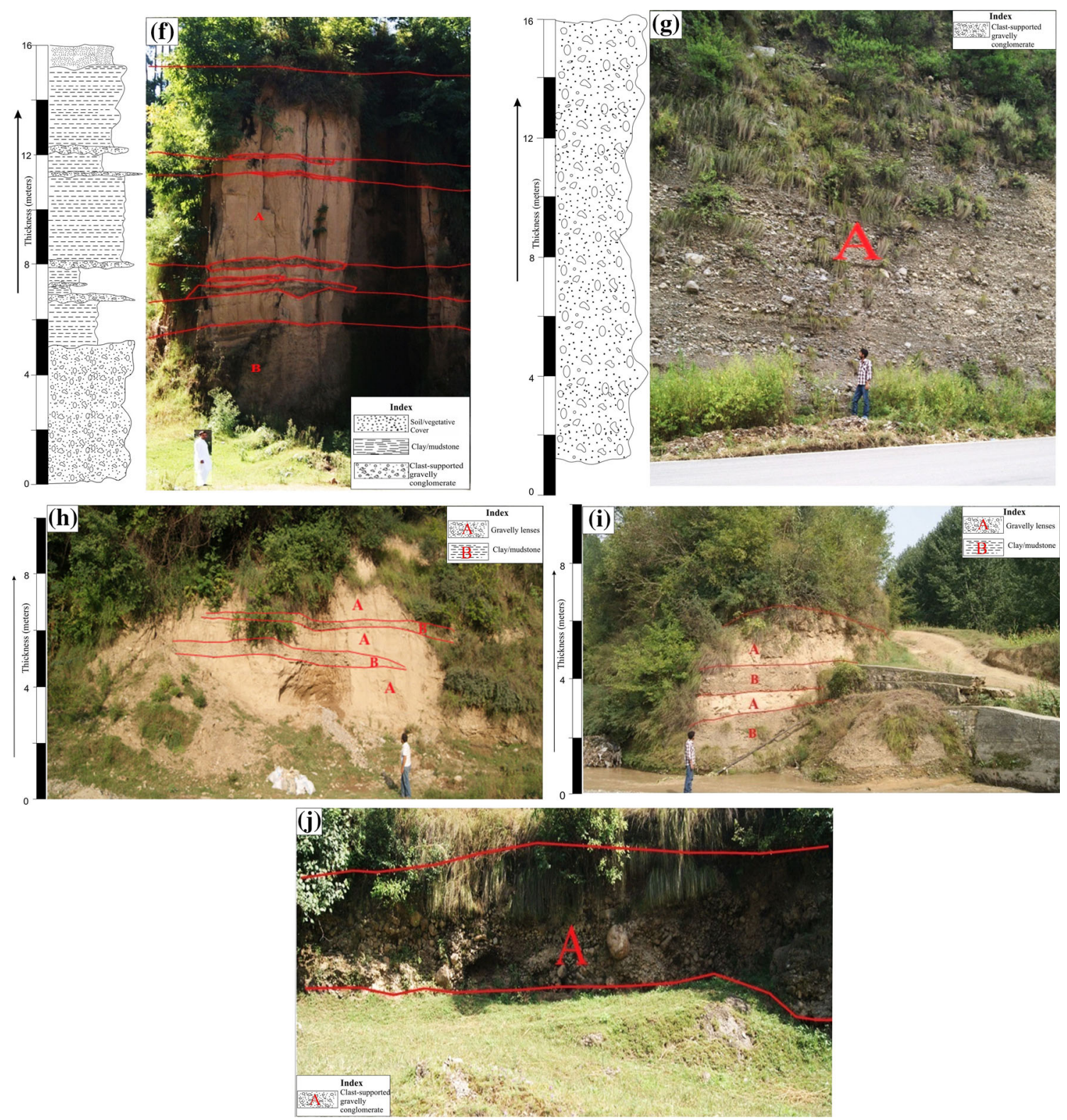

Figure 4. (Continued.)

(figure 5). It is evident from the lithological profiles and Fence diagram that the study area is composed of loose and indurated Quaternary alluvium sediments such as fine to medium silt and clay and large to medium size gravels, cobbles and boulders forming various types of conglomerates (clast-supported or matrix supported).

\subsection{Mapping sediment thickness}

The processed data were interpreted quantitatively to develop a relationship between peak frequency and sediment thickness following the SESAME (2004) guidelines and two basic assumptions of Albarello et al. (2011) are considered, i.e.,
(1) Rayleigh waves in the fundamental mode dominated by ambient vibration wave field, and (2) these waves propagate within nearly homogeneous soft layer overlying rigid bedrock. The assumptions of Nakamura (1989) about the origin of fundamental frequencies is related to shear wave resonance in a single layer of sediment, and in this assumption the layer thickness can be related to fundamental peak frequency of $\mathrm{H} / \mathrm{V}$ spectral ratio by $f_{r}=n V_{s} / 4 H$ where $n$ is uneven integers and $V_{s}$ is the shear wave velocity of sediment. Khan and Khan (2016) gave another assumption that shear wave velocity $\left(V_{s}\right)$ as function of depth $(d)$ can be described as $V_{s}(d) \approx V_{o}(1+d)^{x}$ (where $V_{o}$ is average shear wave velocity at $1 \mathrm{~m}$ below the 


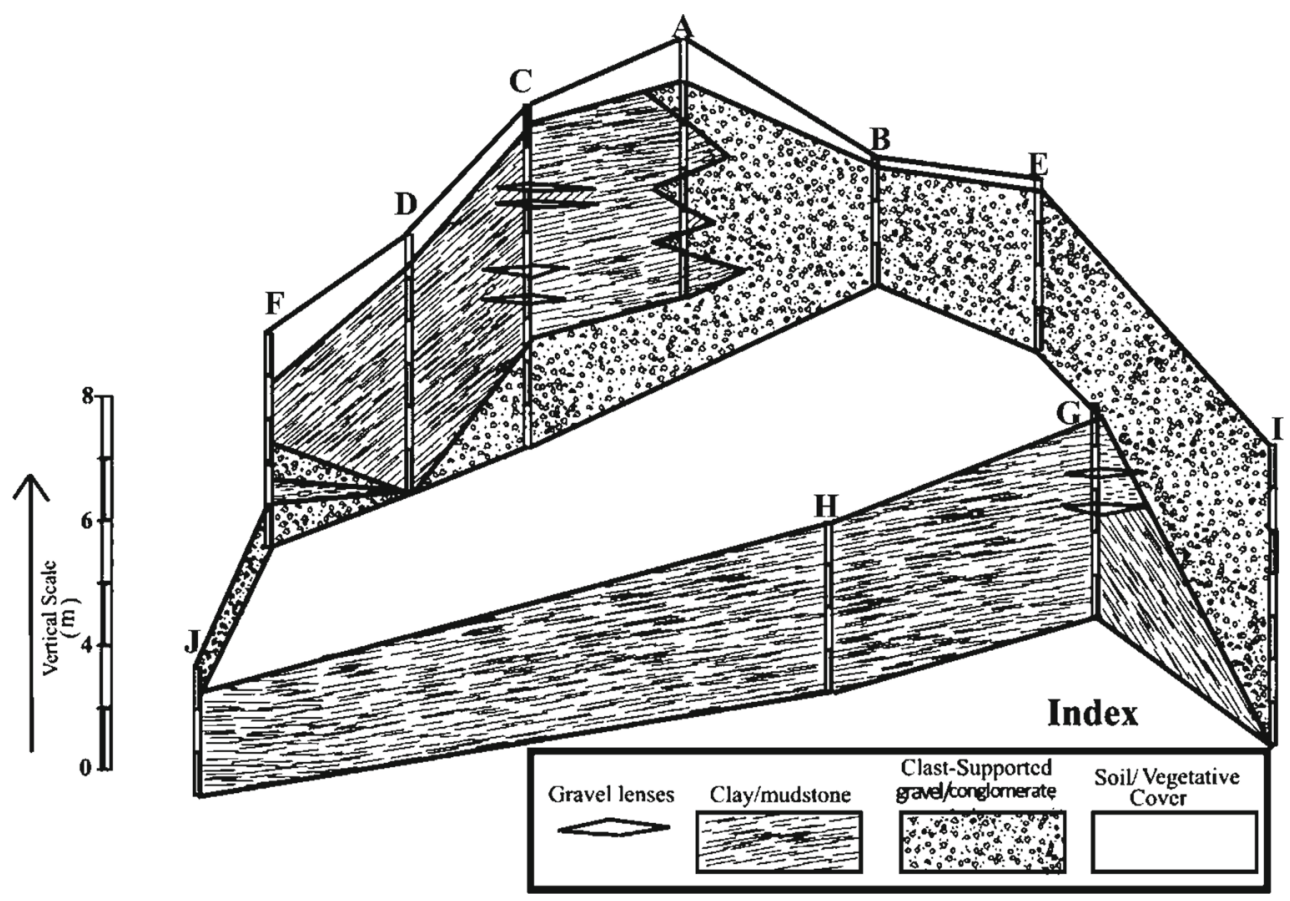

Figure 5. Fence diagram showing the sedimentological characteristic of the Abbottabad basin, developed based on lithological profiles. Alphabet letters show position of lithological profiles.

surface, the constant $x$ can be determined experimentally from the geotechnical borehole data). In the current study, we find the values of $V_{o}$ $(184.41 \mathrm{~m} / \mathrm{s})$ and $x(0.147)$ from 119 geotechnical boreholes using the method of Khan and Khan (2016). Experimental studies in soil layers show that a significant negative correlation exists between the values of $V_{o}$ and $x$ because the stronger the lithostatic load effect (i.e., higher the $x$ ), lower the expected value of $V_{s}$ at the surface (Ibs-Von Seht and Wohlenberg 1999; Albarello et al. 2011).

From the work of Ibs-Von Seht and Wohlenberg (1999), the velocity function can be integrated with fixed parameters of $x$ and $V_{o}$ (calculated from borehole geotechnical borehole data) to find a simple relationship between frequency and overburden sediment thickness (Albarello et al. 2011) as:

$$
h=\sqrt[(1-x)]{\frac{V_{o}(1-x)}{4 f_{r}}+1}-1
$$

where $h=$ sediment layer thickness, $V_{o}=$ surficial shear wave velocity at $1 \mathrm{~m}$ depth, $x=$ functional depth, and $f_{r}=f_{o}$ (fundamental frequency of sediment).

Using this general relation, a power law function $\left(m=a f^{b}\right)$ between the thickness and the frequency of the main peak in $\mathrm{H} / \mathrm{V}$ spectra was established. A relationship by fitting power law regression yielded equation (2). The constant parameters $a=74.628$ and $b=-1.141$ were obtained empirically by fitting the power law function as did the work by the pioneer's researchers Ibs-Von Seht and Wohlenberg (1999) and Albarello et al. (2011). These parameters can be used for sites where independent information about the sediment thickness is available

$$
m=74.628 f_{0}^{-1.141} \text {. }
$$

The sediment thickness values obtained from Tromino data were used to prepare the sediment thickness map of the study area, divided into two zones ' $\mathrm{A}$ ' and ' $\mathrm{B}$ ' on the basis of sediment thickness. Zone 'A' include Kakul, COMSATS University area, Dhamtour, Diswal village, Basti Saleem, Banda Ali Khan and Banda Qazi, and has sediment thickness $<30 \mathrm{~m}$, while zone ' $\mathrm{B}$ ' is comprised of main cities, Mandian, Nawashahr, Narrian, Lambi Deri, supply area, Malik Banda and lower Malik Pura showing higher sediment depth $>30 \mathrm{~m}$. The sediment thickness map is shown in figure 6 .

Seismic waves travel slowly through soft soils compared to hard rock. At the hard rock vs. soft soil interface such as in the basin, the seismic wave's frequency is reduced and trapped in 


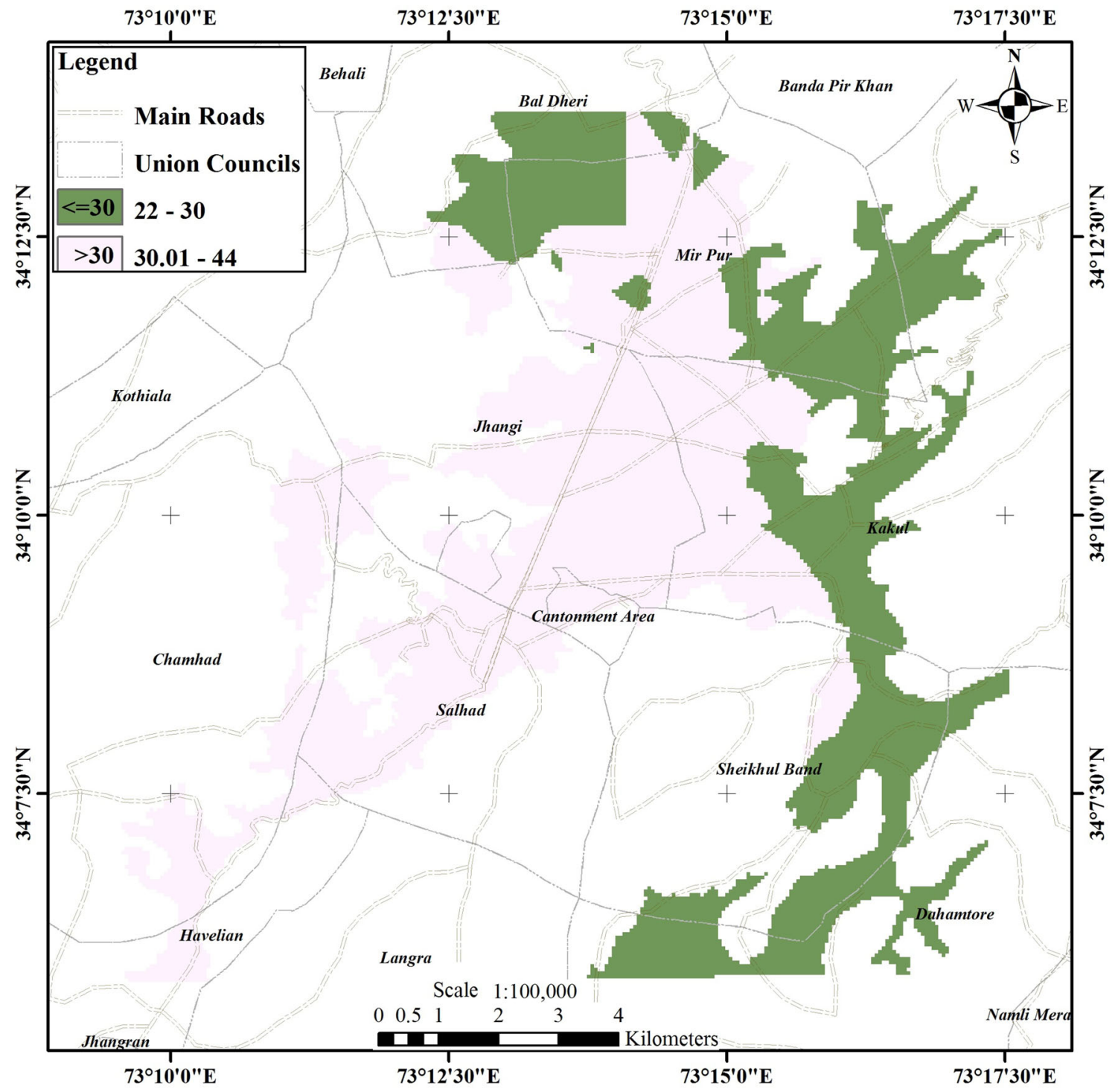

Figure 6. Sediment thickness map for the Abbottabad basin and surrounding area.

soft soils with increased amplitude that results in higher levels of shaking for extended times. Since the study area is an intermontane basin consisting of alluvial deposits and has a large effect on ground motions. According to the sediment thickness map of the study area, southern and central parts of the basins have a larger thickness of alluvial deposits than surrounding areas, hence the earthquake shaking duration will be greater in these parts of the basin.

\section{Results and discussion}

The lithological profile and resultant Fence diagram shed valuable light on the geomorphic and depositional settings of the Abbottabad basin. As is noticed from the profiles that some outcrops are exclusively made up of weakly consolidated, clast-supported conglomerates (profiles 4b, j, g), while others are exclusively comprised of muds and clays (profiles 4a, d, e). The latter, locally contain lenses of gravels (profiles $4 \mathrm{i}$ and $\mathrm{h}$ ). Few outcrops show clay/mud layers alternating gravel layers at equal intervals (profiles $4 \mathrm{f}$ and c). As revealed by the Fence diagram, the lithologies representing conglomerates are predominant at the NE edge of the basin, whereas the western parts of the basin, especially in the southeast part of the city that hosts the core of the city dwellings comprises of mud/clay. Based on the above mention geomorphic profile and Fence diagram, the proximal side of basin (including profiles $4 \mathrm{~b}, \mathrm{j}, \mathrm{g}$ ) is mostly composed of loose, indurated materials such 


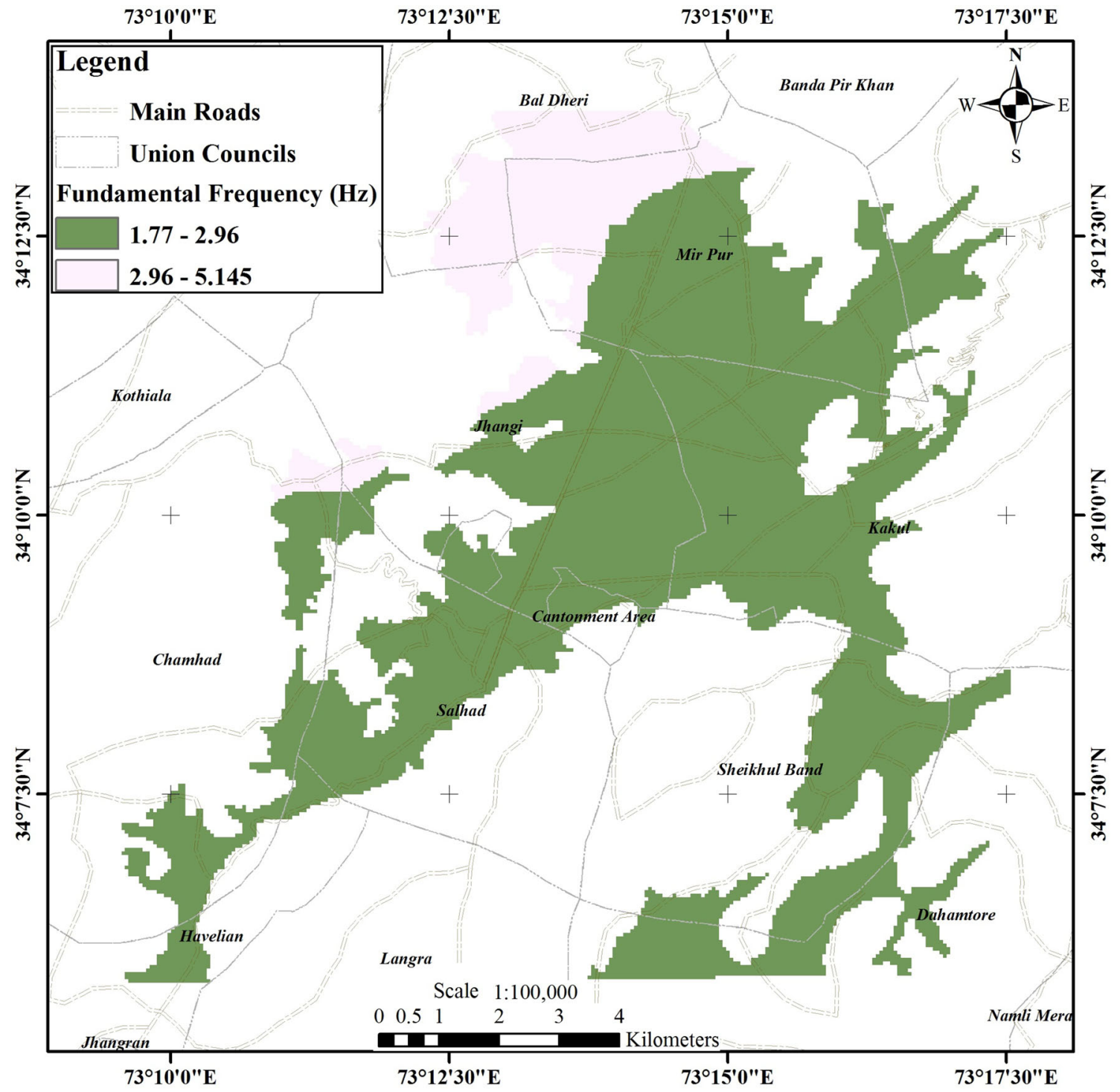

Figure 7. Distribution of fundamental frequency in the Abbottabad basin and surrounding area.

as clast-supported gravel and conglomerate (gravel, cobbles, pebbles and boulders) while the distal side of the basin (including profiles $4 \mathrm{f}, \mathrm{c}, \mathrm{i}, \mathrm{e}, \mathrm{d}, \mathrm{h}$ ) is comprised of fine to medium grain silt, clay and mud.

This sediment-distribution that is revealed from the lithological profiles and Fence diagrams carries strong implications for (1) basin architecture and depositional environments, and (2) seismic amplifications. Firstly, the overall geomorphological settings of the basin are characterized by bedrocks in the surrounding hills, wide multichannels entering part of the basin in the north and finally a restricted drainage at the southern end of the city through a gorge, suggesting a funnel-shaped basin. This particular geomorphological shape of the basin points to free entry of streams (and stream load) from north-northeast but restricted drainage out of the basin at the southern gorge adjacent to the Sirban Hill. This setting suggests that several times in the history of the basin development, the study area was ponded forming a lake that resulted in the sediment deposition, i.e., gravels in the northeast and muds and clays in the southern core of the basin.

From the seismic hazard point of view, various soil types have different shear wave velocities, which determine the amplification of seismic waves resulting in different levels of shaking. Muds/clays have shear wave velocity of $200 \mathrm{~m} / \mathrm{sec}$, whereas mixtures of mud and gravels have shear wave velocity of $350 \mathrm{~m} / \mathrm{sec}$. The muds and clays, if saturated with water are further dangerous as these are not only susceptible to high values of shaking. 
Table 1. Calculated values of shear wave velocity, sediment thickness and fundamental frequency for the Abbottabad basin and surroundings.

\begin{tabular}{|c|c|c|c|c|c|c|}
\hline Location & Longitude & Latitude & $\begin{array}{l}\mathrm{V}_{\mathrm{s}} 30 \\
(\mathrm{~m} / \mathrm{s})\end{array}$ & $\mathrm{SC}$ & $\begin{array}{l}\text { Fundamental } \\
\text { frequency }\left(f_{o}\right)\end{array}$ & $\begin{array}{c}\text { Sediment } \\
\text { thickness }(\mathrm{m})\end{array}$ \\
\hline Police line & 73.2 & 34.14 & 313 & $\mathrm{D}$ & 1.78 & 39 \\
\hline Bar club & 73.21 & 34.14 & 340 & $\mathrm{D}$ & 2.03 & 33 \\
\hline Football ground & 73.22 & 34.14 & 353 & $\mathrm{D}$ & 2.47 & 27 \\
\hline District account & 73.25 & 34.14 & 301 & $\mathrm{D}$ & 1 & 3 \\
\hline Shimla Phari & 73.2 & 34.15 & 362 & $\mathrm{C}$ & 3.88 & 16 \\
\hline Nawashahr & 73.21 & 34.15 & 377 & $\mathrm{C}$ & 1.38 & 25 \\
\hline Lady garden & 73.22 & 34.15 & 327 & $\mathrm{D}$ & 1.81 & 38 \\
\hline Cricket stadium & 73.26 & 34.15 & 578 & $\mathrm{C}$ & 1.1 & 10 \\
\hline Narian town & 73.23 & 34.16 & 353 & $\mathrm{D}$ & 1.19 & 61 \\
\hline Jamia Islamia & 73.24 & 34.16 & 310 & $\mathrm{D}$ & 2.5 & 26 \\
\hline Jughyan bridge & 73.25 & 34.16 & 347 & $\mathrm{D}$ & 3.56 & 17 \\
\hline Ilyasi masjid ground & 73.26 & 34.16 & 341 & $\mathrm{D}$ & 1.47 & 48 \\
\hline Bamlyal & 73.27 & 34.16 & 335 & $\mathrm{D}$ & 2.38 & 28 \\
\hline Qureshi pump & 73.22 & 34.17 & 350 & $\mathrm{D}$ & 1.72 & 40 \\
\hline Bilal town & 73.23 & 34.17 & 347 & $\mathrm{D}$ & 1.09 & 68 \\
\hline Manzoor colony & 73.24 & 34.17 & 351 & $\mathrm{D}$ & 1.28 & 57 \\
\hline New Abadi & 73.25 & 34.17 & 324 & $\mathrm{D}$ & 1.44 & 49 \\
\hline Ilyasi masjid & 73.26 & 34.17 & 361 & $\mathrm{C}$ & 3.84 & 16 \\
\hline Lambi deri & 73.22 & 34.18 & 346 & $\mathrm{D}$ & 2.78 & 23 \\
\hline Pak radio & 73.23 & 34.18 & 350 & $\mathrm{D}$ & 1.19 & 61 \\
\hline Jinnah abad & 73.24 & 34.18 & 302 & $\mathrm{D}$ & 3.09 & 21 \\
\hline Kanj masjid & 73.26 & 34.18 & 314 & $\mathrm{D}$ & 2.16 & 31 \\
\hline Jangi saydan (a) & 73.22 & 34.19 & 371 & $\mathrm{C}$ & 3.84 & 16 \\
\hline Jangi saydan (b) & 73.23 & 34.19 & 319 & $\mathrm{D}$ & 2.5 & 26 \\
\hline $\begin{array}{l}\text { Agriculture Research } \\
\text { Station, Mandian }\end{array}$ & 73.24 & 34.19 & 314 & $\mathrm{D}$ & 1.56 & 45 \\
\hline Abbottabad & 73.25 & 34.19 & 522 & $\mathrm{C}$ & 0.5 & 7 \\
\hline Basali (Girls School) & 73.27 & 34.19 & 450 & $\mathrm{C}$ & 0.7 & 2 \\
\hline Army Med. College (a) & 73.22 & 34.2 & 461 & $\mathrm{C}$ & 7.47 & 8 \\
\hline Ayub Med. College (a) & 73.23 & 34.2 & 333 & $\mathrm{D}$ & 1.16 & 63 \\
\hline COMSATS & 73.24 & 34.2 & 333 & $\mathrm{D}$ & 1.56 & 45 \\
\hline Mirpur & 73.25 & 34.2 & 340 & $\mathrm{D}$ & 1.56 & 45 \\
\hline Kakul & 73.28 & 34.2 & 330 & $\mathrm{D}$ & 1.84 & 37 \\
\hline Banda Ali Khan & 73.22 & 34.21 & 493 & $\mathrm{C}$ & 8.13 & 7 \\
\hline Army Med. College (b) & 73.23 & 34.21 & 334 & $\mathrm{D}$ & 3.25 & 19 \\
\hline Ayub Med. College (b) & 73.24 & 34.21 & 339 & $\mathrm{D}$ & 1.88 & 36 \\
\hline Basic health unit & 73.25 & 34.21 & 321 & $\mathrm{D}$ & 2.44 & 27 \\
\hline Kakul & 73.27 & 34.21 & 731 & $\mathrm{C}$ & 2 & 2 \\
\hline Basti Saleem & 73.23 & 34.22 & 344 & $\mathrm{D}$ & 1.81 & 38 \\
\hline Educator school & 73.24 & 34.22 & 324 & $\mathrm{D}$ & 2.5 & 32 \\
\hline $\begin{array}{l}\text { Abbottabad public } \\
\text { school }\end{array}$ & 73.24 & 34.23 & 471 & $\mathrm{C}$ & 8.59 & 6 \\
\hline
\end{tabular}

The range of the fundamental frequency at the studied area is measured from 0.1 to $10 \mathrm{~Hz}$ (figure 7; table 1). Based on available borehole and Tromino data, sediment depth of the study area was found to be around $30 \mathrm{~m}$. Ibs-Von Seht and Wohlenberg (1999) proposed a simple approximate relationship, which is used to estimate the sediment thickness from the Tromino data. The shear wave velocity obtained from Trominio Engy and SPT $(N)$ was used to classify the soils in the Abbottabad basin using National Earthquake Hazard Reduction Program (NEHRP 1997) soil classification scheme. According to NEHRP (1997), the study area is classified as 'Site Class C' and 'Site Class D'. 


\section{Conclusions}

- Much of the Abbottabad city, especially its most densely populated inner city from supply to the south is underlain by muds/clays for several tens of meters. As much of the natural drainage is blocked by immense population, the water entering the basin is drained internally into the soils, which further aggravates the seismic stability of the city.

- The site classification map shows that the main city of Abbottabad has low shear wave velocity and high seismic risk as compared to surrounding area of the basin (includes Kakul, Dhamtour, Banda Qazi and Malik Banda). The studied area shows that greater parts of the basin including the main city and surrounding areas have an average frequency from 0.1 to $10 \mathrm{~Hz}$ (figure 7). The frequency map of the Abbottabad basin shows that it consists of alluvial deposits (i.e., stiff and dense soil). The fundamental frequency for bedrocks is $>10 \mathrm{~Hz}$, which is not the case in the Abbottabad basin.

- The greater sediment thickness is in the zone B, i.e., the central core of the city that shows greater vulnerability to the seismic hazard in this densely populated area.

\section{Acknowledgements}

This study is part of the M.Phil thesis at the National Centre of Excellence in Geology (NCEG), University of Peshawar. The instrumentation used in this study and all logistic support for the fieldwork were provided by the NCEG, which is gratefully acknowledged. Assistance in field and use of Grilla software by Ahmad Hammad Khaliq and Mian Luqman Hussain is greatly appreciated.

\section{References}

Albarello D, Cakir R and Walsh T J 2011 Testing joint application of HVSR ambient vibration measurements and MASW seismic survey in the Puget Lowland and
Coastal Area, Washington; Seismol. Res. Lett. 82(2) 300 .

Alvarez W 2010 Protracted continental collisions argue for continental plates driven by basal traction; Earth Planet. Sci. Lett. 296(3-4) 434-442.

DiPietro J A and Pogue K R 2004 Tectonostratigraphic subdivisions of the Himalaya: A view from the west; Tectonics 23, https://doi.org/10.1029/2003TC001554.

Hussain A, Yeats R S and MonaLisa 2009 Geological setting of the 8 October, 2005 Kashmir earthquake; J. Seismol. 13(3) 315-325.

Ibs-Von Seht M and Wohlenberg J 1999 Microtremor measurements used to map thickness of soft sediments; Bull. Seismol. Soc. Am. 89 250-259.

Khan S and Khan M A 2016 Mapping sediment thickness of the Islamabad city using empirical relationships: Implications for seismic hazards assessment; $J$. Earth Syst. Sci. 125(3) 623-644, https://doi.org/10. 1007/s12040-016-0675-0.

Latif M 1970 Explanatory notes on the geology of southeastern Hazara to accompany the revised geological map; Jahrb Geol. Bundesanst 15 5-20.

Grilla Software 2012 Software for passive/active surface wave analysis and modeling and vibration analysis, Italy (www. tromino.it).

GSP 2002 Geological map of Abbottabad area NWFP, Pakistan; Map series Vol. III, no. 97, Scale 1:50,000, Issued by Gauhar S H, Director General, Geological Survey of Pakistan.

MonaLisa, Khwaja A A and Jan M Q 2007 Seismic hazard assessment of the NW Himalayan fold-and-thrust belt, Pakistan, using probabilistic approach; J. Earthq. Eng. 11(2) 257-301.

Nakamura Y A 1989 A method for dynamic characteristics estimation of subsurface using microtremor on the ground surface; Quarterly Rep. RTRI 30(1).

NEHRP 1997 Commentary on the guidelines for the seismic rehabilitation of buildings. Federal Emergency Management Agency, Washington DC, USA.

Seeber L and Armbruster J 1979 Seismicity of the Hazara arc in northern Pakistan: Decollement vs. basement faulting; In: Geodynamics of Pakistan, Geological Survey of Pakistan, Quetta, pp. 131-147.

SESAME 2004 Guidelines for the implementation of the $\mathrm{H} / \mathrm{V}$ spectral ratio technique on ambient vibrations; SESAME European Project.

Shahzada K 2011 Seismic risk assessment of buildings in Pakistan; PhD Dissertation, University of Engineering and Technology, Peshawar, Pakistan.

Tahirkheli R K, Mattauer M, Proust F and Tapponnier P 1979 The India Eurasia suture zone in northern Pakistan: Synthesis and interpretation of recent data at plate scale; In: Geodynamics of Pakistan, Geological Survey of Pakistan, Quetta, pp. 125-130. 